\title{
Nanotransformations in the blanket of materials at the combined processing by untied granules
}

\author{
V. P. Smolentsev ${ }^{1}$, A. V. Kuzovkin ${ }^{2}$ \\ ${ }^{1}$ Voronezh state technical university, 14, Moskovsky Avenue, Voronezh, 394026, Russia \\ E-mail:vsmolen@inbox.ru
}

\begin{abstract}
Summary: Nanotransformations of a blanket at the fair dimensional combined processing with imposing of electric field the tool in the form of untied metal granules are considered. An object of researches are the figurine details applied in aviation, the missile and space equipment and in the oil and gas industry: driving wheels and a flowing part of cases of turbo-pump units, screws, krylchatka where there are sites of variable curvature with limited access of the tool in a processing zone. It is shown that the combination in the combined process of two-component technological environments of current carrying granules and the electroconductive liquid environment given with a high speed to a processing zone allows to receive the required quality of a blanket; action of electric field from a source with the increased tension allows to create at fair dimensional processing the required peening from blows of firm granules. It gives the chance to raise a resource and durability of responsible knots of the aerospace equipment and oil and gas equipment, to expand the field of use of the combined processing with untied granules on a detail with the sites not available to processing by a profile electrode.
\end{abstract}

Keywords: the combined processing; untied granules; the two-component environment; the mechanism of management

\section{Introduction}

In aviation and the missile and space equipment is available details spoluzakryty cavities which are difficult for processing the profile tool. In cavities it is necessary to develop the modes and ways for obtaining the required quality of a blanket ${ }^{[1,2]}$, the providing directed nanotransformations of properties of materal of details in the course of the combined processing. For this purpose follows at fair processing in a blanket of material to carry out the nanotransformations providing a surface roughness within $\mathrm{Ra}=0,32-0,63$ of a micrometer and squeezing internal residual tension in detail material.

\section{Mechanism of formation of microroughnesses}

The combined processing with a filler, irrespective of the used scheme, is intended for finishing operations of formation of a blanket of a detail, i.e. at that stage of technological process when there is a formation of characteristics of quality of the processed surface of a detail including on a nanolevel. The firm granules which are a part of a liquid component of the technological environment are the tool which, having considerable energy, makes decrease in microroughnesses of a surface and creation of internal microtension. These factors considerably define operational indicators of a detail. The blanket is characterized by two key parameters: a roughness of a surface and physicomechanical properties which have significant effect on wear resistance, durability, resistance to fatigue and sign-variable loadings and other similar factors.

\section{Technique of researches}

The research of a condition of a blanket was made by a standard technique and consisted in a research of samples by means of production of cross mikroshlif of the processed surfaces. Mikroshlifa were exposed to special chemical processing and etching for identification of structure of material and to their further studying on optical and electronic microscopes. Besides, on samples, in the location of a near-surface layer with the changed structure and 
hardness the measurement of microhardness by introduction of indentor on slanting cuts was made.

The condition of a blanket of a detail in case of influence of all technology factors was originally determined (the combined processing by the scheme with anode dissolution of a surface of a detail and its plastic deformation of a firm component of a working environment): anode dissolution of material of preparation and removal of a hereditary layer and simultaneous hardening of a surface of a firm component of a working environment. The surface condition after processing can be estimated by several characteristics: the size of microhardness and depth of its bedding, character of residual tension, a roughness of a surface and structure of material in a near-surface layer, i.e. in that layer which perceives the main electrochemical and mechanical influences of a two-component working environment.

\section{Discussion of results of researches}

Researches showed that the greatest influence on process of formation on a nanolevel of a blanket of a detail is played by parameters of the movement of a filler and its physicomechanical properties. Metalgraphic researches revealed at the changed layer from 4 to 12 microns in depth with the maximum peening directly at the upper bound of this layer is model. Photos of mikroshlif of the studied samples before processing are presented in fig. 1. Various materials having a different hereditary blanket were subjected to processing. Besides, conditions and the modes of processing varied.

The sample from steel 40XH2MA (fig. 1, a and b) was received by draft milling and will subject to elektrokhimikomekhanichesky processing (EHMP) at more "rigid" modes: granules of a filler were made of steel 45 by the size $\mathrm{d}=5 \mathrm{~mm}$; concentration in $\mathrm{MEP}$ - 25 - 30\%; electrolyte $15 \% \mathrm{NaCl}$ solution; the scheme of giving of granules told them high kinetic energy - about $10 \mathrm{~m} / \mathrm{s}$ (calculated value); working tension on electrodes - $75 \mathrm{~V}$; the general distance from a hydraulic element to a detail surface $-50 \mathrm{~mm}$; processing time, as well as in the previous case made 40 seconds.

In photos of mikroshlif (fig. 1) on a nanolevel the uniform changed superficial microlayer of metal of which more dense arrangement of grains of material is characteristic is clearly visible. Measurement of microhardness showed its increase due to mechanical influence of a filler up to HRCE value 43.5 that above than at preparation where this indicator makes 35.5 HRCE. Change of microhardness of a blanket of a detail proves formation in it internal, and as by us it was established - the squeezing microtension. At boundary, greatest possible at the used schemes of processing and the equipment, the processing modes (the photo on rice $1 ; 2, a, b$ ), the size of a peening made Un $\approx$ of $22,5 \%$ at the general depth of $\mathrm{hn} \approx$ of 10 microns. The maximum of a peening is observed at its upper bound.

The sample presented in fig. $1 \mathrm{c}$ and $\mathrm{d}$, was made of steel $38 \mathrm{H} 2 \mathrm{MYA}$, and fair milling was the previous operation of machining. At its processing "the soft modes" were used: diameter of the granules of a filler made of the most widespread steel 45 , equaled $5 \mathrm{~mm}$; their concentration in a total amount of a working environment - $25-30 \%$; as electrolyte fifteen percentage solution of chloride of $\mathrm{NaCl}$ sodium were used; granules moved to the processed surface with the rated speed of $5 \mathrm{~m} / \mathrm{s}$; working tension on electrodes - $50 \mathrm{~V}$; size MEP - $50 \mathrm{~mm}$; time of processing of the area of a detail equal to an effective spot made 40 seconds. Mikroshlify of this sample reflect existence of the strengthened layer with depth of $\mathrm{hn} \approx 4,5$ microns and $\mathrm{Un} \approx 13,5 \%$. On a surface of a detail there are no microcracks and a mikrorastravlivaniye on borders of grains in the strengthened layer. It demonstrates presence of the squeezing residual tension which increases the fatigue durability of a detail. The performed measurement of microhardness, showed that unlike not changed state (34.5 HRCE) it increased due to processing up to the size of $39.5 \mathrm{HRCE}$.

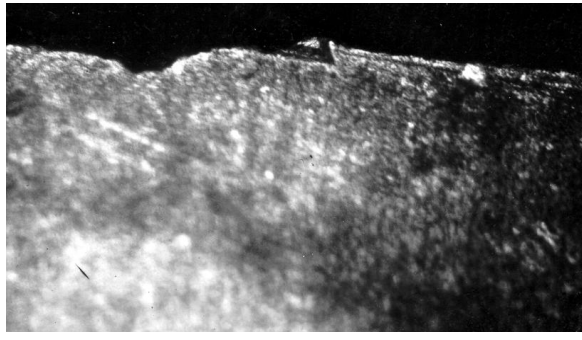

a

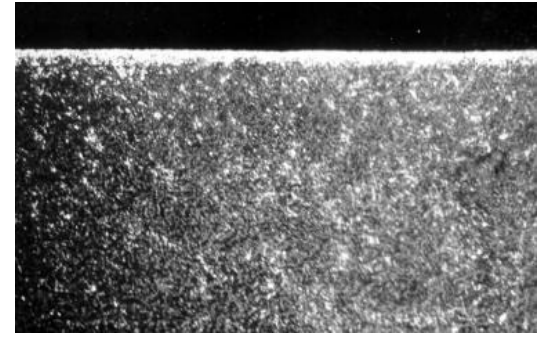

$\mathrm{b}$ 


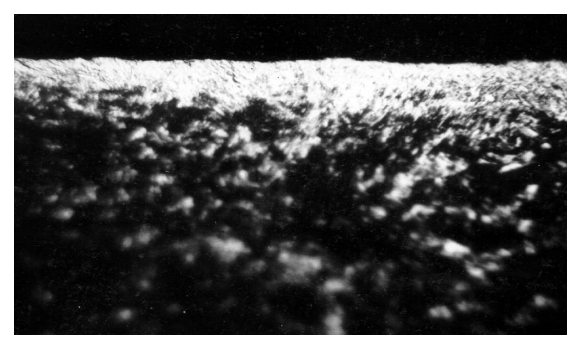

C

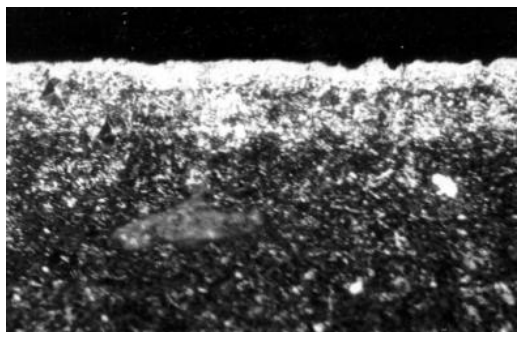

d

Figure 1: Results of a research of a blanket of the detail subjected to elektrokhimikomekhanichesky processing with use of a

filler and imposing of electric field: a - steel 40XH2MA before processing (increase by 200 times); b - steel 40XH2MA after processing (increase by 200 times); c, d - steel 38H2MYA after processing (increase in 200 and 320 times)

The research of an external surface of the samples characterized earlier at various sizes of an interelectrode interval (MEP) was made for visual assessment of results of the combined processing with use of a firm conducting filler. Photos of an external surface of samples from steel 38H2MYuA are presented in fig. 2. The appearance of a surface of samples from steel 40XH2MA received at change of size MEP from 40 to $70 \mathrm{~mm}$ is given in fig. 3, other technological modes of processing when carrying out an experiment did not change.

The analysis of these surfaces allows to draw a conclusion that when processing with a filler there is no rastravlivaniye on borders of grains of material of a detail. Some decrease in size of a roughness of a surface of a detail at increase in MEP can be explained with decrease in amount of total energy of the working environment participating in a shaping. Similar experiments were made for other processed materials.

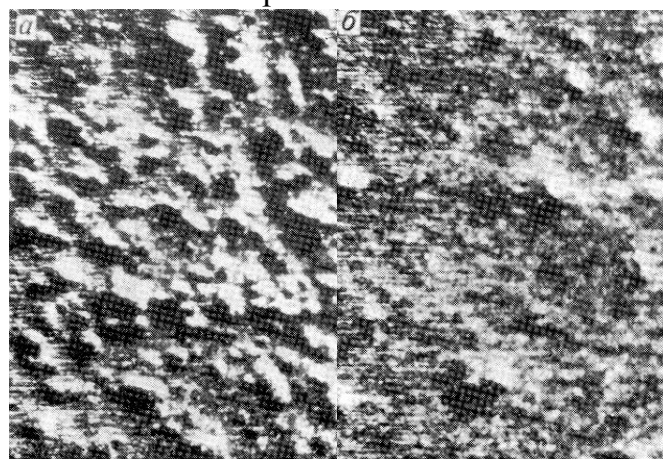

Figure 2: Shlif is exemplary from steel 38H2MYA after EHMP at various sizes MEP: a - size MEP is 35 - 40 mm; b - size

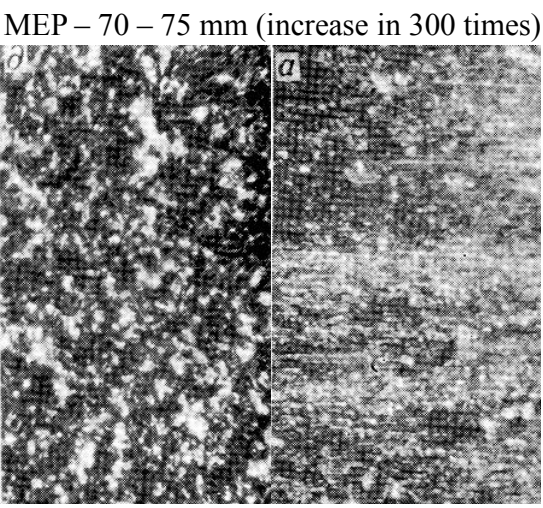

Figure 3: Shlifa of samples from steel 40XH2MA after EHMO at various sizes MEP: a - size MEP is 40 - $42 \mathrm{~mm}$; b - size MEP

\section{Conclusion}

$-70-71 \mathrm{~mm}$ (increase in 300 times)

To the main scientific results, the received authors, it is necessary to carry:

- elements of the theory of nanotransformations and the method of a dimensional shaping based by complex influence on a nanolevel of the electric field providing electrochemical dissolution of nanolayers of an allowance, and untied granules of the tool; 
- justification of influence of the dimensional combined processing with a filler on change of nanostructure of a blanket of a detail that provides high-quality preparation of a surface under anode removal of an allowance at achievement of the set characteristics of quality of a blanket providing increase in operational properties of products;

The practical value of researches consists in:

1. Creation of process of the dimensional shaping of details of conducting materials which allowed to expand the field of technological use of electrochemical processing with a firm conducting filler on a dimensional shaping of surfaces of various profile, remote for the tool.

2. Implementation dimensional a shaping of details of difficult geometry with obtaining the required characteristics of quality of a blanket that gives the chance to raise operational characteristics of products.

3. Creation of technological processes of a dimensional shaping of the surfaces, remote for the integral tool, which allowed the technologist to the mechanician to expand the knowledge base on EHMO with a firm conducting filler.

4. Implementation of the technology solution of a problem of dimensional processing of surfaces of the details located under a negative corner to an axis of symmetry of a stream of a working environment (the patent of Russia ${ }^{[1]}$ ) and thin-walled details (the patent of Russia ${ }^{[2]}$ ).

\section{References}

1. Patent of Russia No. 2166417. The device for the combined electroprocessing /Смоленцев ВП, Kuzovkin AV, Boldyrev AI, Smolentsev GP//Byul.Izobr., 2001, No. 13.

2. Patent of Russia No. 2072281. A filler granule for the combined electroprocessing /Смоленцев ВП, Boldyrev AI, Kuzovkin AV//Byul.Izobr., 1997, No. 3. 